\title{
The effect of loupes on neck pain and disability among dental hygienists
}

\author{
Melanie J. Hayes ${ }^{\mathrm{a}, *}$, Peter G. Osmotherly ${ }^{\mathrm{b}}$, Jane A. Taylor ${ }^{\mathrm{b}}$, Derek R. Smith ${ }^{\mathrm{b}}$ and Alan Ho ${ }^{\mathrm{b}}$ \\ ${ }^{a}$ Melbourne Dental School, The University of Melbourne, Melbourne, VIC, Australia \\ ${ }^{\mathrm{b}}$ School of Health Sciences, The University of Newcastle, Callaghan, NSW, Australia
}

Received 8 August 2014

Accepted 19 March 2015

\begin{abstract}
.
BACKGROUND: Musculoskeletal disorders represent a significant occupational health issue in dental hygiene, with high prevalence rates documented. Despite this fact, there have been few advancements in the application of ergonomic principles in the dental hygiene profession. While the use of loupes is often promoted as an ergonomic solution, there is little published research to support this claim.

OBJECTIVES: The aim of the present study, therefore, was to investigate the effect of the use of loupes on neck pain and disability in dental hygienists.

METHODS: The study was conducted using an exploratory pre-test post-test design, comparing musculoskeletal measures in dental hygienists wearing loupes with final year dental hygiene students who do not wear loupes. Pre- and post-test measures included the Neck Pain and Disability Scale and a standardised physical assessment using previously validated measures. Statistical analysis was conducted as a series of mixed ANOVAs with time and treatment as the independent variables.

RESULTS: While the analyses revealed no significant interactions between time and treatment $(p<0.05)$, there were general trends of improvement or deterioration for outcome measures. Improvements over time were noted in the treatment group for cervical range of motion and deep neck muscle endurance; however deteriorations were noted for forward head posture and cervical kinaesthetic sense.

CONCLUSIONS: Overall, despite no statistically significant differences being detected, this study suggests that wearing loupes appears to have both positive and negative outcomes with regards to physical well-being. As such, further studies are required to more precisely determine the effects of loupes on MSD among dental hygienists, particularly long-term. Dental hygienists with existing neck pain exploring ergonomic equipment may reflect on the findings and consider the potential benefits and risks of wearing loupes.
\end{abstract}

Keywords: Musculoskeletal disorders, risk factors, magnification

\section{Background}

\subsection{Musculoskeletal disorders in the dental hygiene profession}

Musculoskeletal disorders (MSD) represent a significant and costly occupational health issue for the dental profession [1-4]. Work related MSD include injury, trauma and pain to both the soft and hard

*Address for correspondence: Melanie J. Hayes, Melbourne Dental School, The University of Melbourne, 720 Swanston Street, Melbourne, VIC 3010, Australia. Tel.: +61 39341 1535; E-mail: melanie.hayes@unimelb.edu.au. tissues of the body, and frequently develop over time [3]. As a preventive dental practitioner, the physical burden of performing repetitive and precise tasks such as scaling and debriding teeth places dental hygienists at a high risk of work related MSD [3, 5]. Recent research supports this observation, with the prevalence of MSD in the profession reported at rates between $64 \%$ and $93 \%$ [3]. Hygienists are more likely to suffer neck, shoulder and wrist pain than other dental professionals [6-8]. Hygienists are also exposed to a number of other identifiable risk factors, such as a large number of occupation related computer usage hours, psychosocial stress 
and being predominately of female gender [3, 9-13]. This occupational health issue leads to lost work time, diminished work performance, medical attention and possible early retirement $[14,15]$. The economic ramifications of this situation are substantial, with lost earnings in the United States of America due to MSD in the dental profession reported at over $\$ 40$ million some years ago [5]. With a considerable proportion of the profession reporting MSD, and the consequent effects and impacts of this, research into the prevention of this problem is imperative.

Neck pain specifically has been identified as a common complaint of dental hygienists, with the 12 month prevalence reported at between 54\% and 69\% $[6,16,17]$. Work-related tasks such as scaling teeth appear to predict reported neck pain among Australian and Swedish dental hygienists, as does the stress of balancing work with family commitments $[18,19]$. Dental hygienists suffering from neck pain are more likely to have time off work or are considering reducing their working hours [18], affecting productivity and career longevity.

It is evident that the problem is widely acknowledged, however much of the information regarding prevention of MSD among dental hygienists appears to be anecdotal [3]. Developing an ergonomic solution has been limited by attention bias when examining postural improvements [20,21], and participants completing undemanding simulated tasks during the intervention [20, 22, 23]. As a result, there has been little development or progression in ergonomics for the dental hygiene profession.

\subsection{Loupes as a preventive measure against $M S D$}

New technologies, such as loupes [surgical magnification] for the dental hygienist are being promoted as a preventive measure for MSD in the profession. Loupes are an eyewear system of telescopes attached to lenses (Fig. 1), which magnify the viewing field; in the case of dental clinicians, this means the teeth and the gingiva [24]. However, there appears to be no longitudinal studies or research using objective measures to support this innovation. The use of surgical magnification when providing dental treatment allows the clinician to maintain their natural posture, which in turn is believed to reduce the risk of musculoskeletal pain or discomfort [25]. It has been suggested that loupes may reduce the physical stresses on the body [26]. While the use of loupes amongst hygienists is not commonplace, it is never-

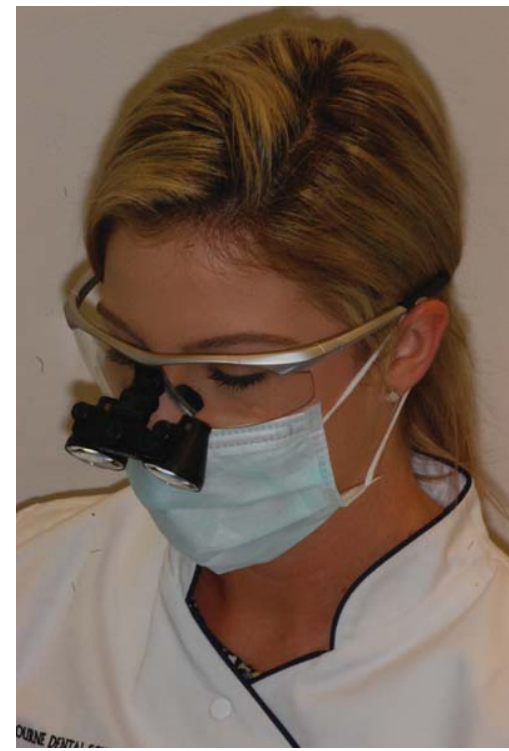

Fig. 1. Dental hygienist wearing loupes.

theless, a tool that hygienists may choose to use in their daily practice. At the current time loupes are not considered to be essential for workplace safety and sound ergonomics.

Current research into the effect of loupes appears to have been limited to self-reported measures of MSD through the use of questionnaires [18, 27, 28], or a single case study reporting a student's experiences [24]. To our knowledge, there is no contemporary research in the literature that has utilised triangulation methods to assess the effectiveness of using loupes on MSD in practising dental hygienists. The use of both self-reporting and objective outcome measures would provide a clearer insight into the potential benefits and limitations to wearing loupes during clinical patient care. The aim of the present study is to investigate the effect of the use of loupes on neck pain and disability in dental hygienists, using triangulation methods.

\section{Methods}

The study was conducted as an exploratory pretest post-test design with a non-equivalent control group, comparing musculoskeletal measures in dental hygienists wearing loupes, with final year dental hygiene students who do not wear loupes. The research project was approved by the University of Newcastle Human Research and Ethics Committee. 


\subsection{The intervention: Loupes}

Subjects in the treatment group were issued with flip-up Galilean loupes in 2.5x magnification. This level of magnification offers the widest field of view and longest depth of focus when compared to higher powers. The flip up function allows the magnification lenses to be adjusted during treatment or flipped out of sight when talking with patients or writing notes. Participants in the treatment group were individually fitted for loupes, measuring the working distance for appropriate fit. Working distance is the distance between the eyes and the oral cavity, and is often crudely proportionate to height. These measurements are crucial for the hygienist to have a clear view of the oral cavity and work in a balanced working position. It has been suggested that poorly fitting loupes can actually exacerbate MSD, given that they may require the clinician to place themselves in an awkward position for optimal vision [25]. The intervention involved subjects wearing the loupes during all clinical care provided to their patients in practice for a period of six months.

\subsection{Outcome measures}

Both self-reported and objective measures of musculoskeletal pain in the neck region were collected. Self-reported measures of neck pain and dysfunction were evaluated by the Neck Pain and Disability Scale (NPDS). The objective measures of upper body musculoskeletal symptoms were evaluated by a physical assessment, following a standardised protocol. The physical assessment included measures of cervical range of movement (CROM), low load craniocervical flexion, cervical proprioception, and craniovertebral angle. Each of these measures are published in protocols elsewhere, and have been established as reliable and reproducible [29-34]. The characteristics of these measures are described in Table 1.

\subsection{Recruitment}

All full members of the New South Wales branch of the Dental Hygienists Association of Australia were contacted via post, and final year dental hygiene students at the University of Newcastle were also approached at the beginning of a clinical session on campus by a person not involved with the project. All those invited received a participant information statement, consent form and self-addressed replypaid envelope. Interested participants who met the inclusion criteria and did not meet any of the exclusion criteria (Table 2), and who voluntarily returned the signed consent form were considered eligible for the study. The minimum sample size required to determine a statistical difference in outcomes was 12 participants in each group, based on the minimal important change of 12 points difference in NPDS scores, a type I error of $\alpha=0.05$ and $80 \%$ power.

\subsection{Procedure}

All participants were required to travel to The University of Newcastle (Ourimbah campus) to complete baseline demographic data collection, the NPDS survey and undergo the physical assessment. At this stage, participants in the treatment group were also personally fitted for loupes. Participants allocated to the treatment group were required to wear loupes during clinical treatment of patients, for the next six months. Participants allocated to the control group were required to work as usual, that is without the use of surgical magnification, for the next six months. Participants in the control group were also required to agree not to use loupes during the study period. At the end of the six month period, participants would again be required to complete the NPDS outcome measure as well as attend The University of Newcastle for a post-test physical assessment.

\subsection{Analysis}

An intention-to-treat analysis was adhered to throughout the study. Tabular summaries of demographic characteristics summarised responses using descriptive statistics, while comparison of the survey data pre- and post-test were performed using mixed ANOVAs. The primary outcome factor was change in neck pain and/or disability.

\section{Results}

A total of 12 practising dental hygienists and 17 final year dental hygiene students consented to participate in the study. The dental hygienists had a mean age of 31.8 (SD, 7.8) years and worked an average of 33.9 (SD, 8.2) hours per week, while the students on average were 25.1 (SD, 4.4) years and completed 28.1 (SD, 11.7) clinical hours per week. Both groups were predominantly non-smoking females. The descriptive statistics of participants are displayed in Table 3. 
Table 1

Outcome measures

\begin{tabular}{|c|c|c|c|c|c|}
\hline Measure & Description & Subjects & ICC & $\begin{array}{l}\text { Reliability } \\
\text { coefficient }\end{array}$ & Author \\
\hline NPDS & $\begin{array}{l}\text { This survey measures neck pain and/or } \\
\text { dysfunction. It consists of } 20 \text { questions } \\
\text { which require the subject to respond on } \\
\text { a visual analogue scale. }\end{array}$ & & 0.97 & 0.93 & Goolkasian [29] \\
\hline $\begin{array}{l}\text { Cervical range of } \\
\text { motion }\end{array}$ & $\begin{array}{l}\text { This testing is performed as per the protocol } \\
\text { described by Youdas et al [30]. Cervical } \\
\text { range of motion will be measured using } \\
\text { a gravity goniometer; active range of } \\
\text { cervical spine motion in the directions of } \\
\text { flexion, lateral flexion and rotation to } \\
\text { either direction will be ascertained. This } \\
\text { test can be used to evaluate neck disorders. }\end{array}$ & Orthopaedic disorders & $0.84-0.95$ & & Youdas [30] \\
\hline $\begin{array}{l}\text { Low load cervical } \\
\text { vertebral flexion }\end{array}$ & $\begin{array}{l}\text { This test is performed as described by } \\
\text { Jull et al. [31]. Pressure biofeedback will } \\
\text { be used to measure deep cervical flexor } \\
\text { muscle endurance using a low load, to } \\
\text { reflect the tonic function of this muscle } \\
\text { group. This test can be used to assess neck } \\
\text { disorders. }\end{array}$ & $\begin{array}{l}\text { Whiplash associated } \\
\text { disorders }\end{array}$ & $0.65,0.89$ & & Jull [31] \\
\hline $\begin{array}{l}\text { Cervical joint position } \\
\text { test }\end{array}$ & $\begin{array}{l}\text { Evaluation of neck proprioceptive activities } \\
\text { will be assessed using the cervical joint } \\
\text { position test as described by Treleaven } \\
\text { et al. [32], following instructions } \\
\text { developed by Revel et al. [33]. This test } \\
\text { may be a predictor of impaired cervical } \\
\text { kinaesthetic sense. }\end{array}$ & Young healthy adults & 0.81 & & Treleaven et al. [32] \\
\hline Craniovertebral angle & $\begin{array}{l}\text { The natural head posture of subjects will be } \\
\text { assessed by taking photographs of the } \\
\text { subjects in seated positions, using markers } \\
\text { to identify the craniovertebral angle, as per } \\
\text { the protocol described by Watson and } \\
\text { Trott [34]. It has been suggested that a } \\
\text { smaller craniovertebral angle (ie forward } \\
\text { head posture) may be a predictor of } \\
\text { headaches and neck pain. }\end{array}$ & Females $25-40$ yrs & & 0.973 & Watson and Trott [34] \\
\hline
\end{tabular}

Table 2

Inclusion and exclusion criteria for the study

\begin{tabular}{|c|c|c|}
\hline Inclusion criteria - dental hygienists & $\begin{array}{l}\text { Inclusion criteria - dental hygiene } \\
\text { students }\end{array}$ & Exclusion criteria \\
\hline $\begin{array}{l}\text { 1. Registration as a dental hygienist } \\
\text { with the Dental Board }\end{array}$ & $\begin{array}{l}\text { 1. Enrolled full-time in the third year } \\
\text { of the Bachelor of Oral Health } \\
\text { Program }\end{array}$ & $\begin{array}{l}\text { 1. Chronic neck or shoulder pain } \\
\text { (persistent pain for at least three } \\
\text { months) }\end{array}$ \\
\hline $\begin{array}{l}\text { 2. Working as a dental hygienist for a } \\
\text { minimum of } 24 \text { hours per week }\end{array}$ & $\begin{array}{l}\text { 2. Completing at minimum of } 24 \\
\text { hours of clinical experience per } \\
\text { week }\end{array}$ & $\begin{array}{l}\text { 2. Pre-existing musculoskeletal } \\
\text { disease/disorder unrelated to } \\
\text { occupational factors (eg } \\
\text { Rheumatoid arthritis, fibromyalgia) } \\
\text { 3. Currently wearing loupes }\end{array}$ \\
\hline
\end{tabular}

Table 4 summarises the neck related self-report and physical measures for the treatment and control groups at baseline and following the intervention. A series of mixed ANOVAs were conducted with time (baseline vs. post-intervention) and treatment (intervention vs. control) as the independent variables. The analyses revealed no significant interactions between time and treatment $(p<0.05)$, which indicates that the loupes created no significant differences in outcomes. There was no change in mean NPDS scores between baseline and follow-up for the treatment group, while the control group reported an increase in perceived neck pain at follow-up. Although not statistically significant, improvements over time were noted in the 
Table 3

Baseline characteristics of study participants

\begin{tabular}{lcc}
\hline & Treatment & Control \\
\hline Age Mean years (SD) & $31.8(7.8)$ & $25.1(4.4)$ \\
Clinical hours per week Mean (SD) & $33.9(8.2)$ & $28.1(11.7)$ \\
Height Mean (SD) & $166.0(6.1)$ & $163.3(9.4)$ \\
Gender (\%) & & \\
$\quad$ Female & 100 & 82.4 \\
$\quad$ Male & 0 & 17.6 \\
Have children (\%) & & \\
$\quad$ Yes & 33.3 & 5.8 \\
$\quad$ No & 66.6 & 94.1 \\
Regular tobacco smoker (\%) & & \\
$\quad$ Yes & 16.7 & 5.8 \\
$\quad$ No & 83.3 & 94.1 \\
\hline
\end{tabular}

treatment group for the tests examining cervical range of motion and low load cervical vertebral flexion; whereas these measures declined over time for the control group. Deteriorations were noted in treatment group participants for forward head posture and joint position sense, while there were improvements in the control group for the same measures.

\section{Discussion}

This study appears to be the first to objectively assess the impact of wearing loupes on neck pain and disability among practising dental hygienists. Development of a standardised protocol, with reliable and repeatable measures ensures a high validity with the study outcomes. Unlike previous research, this study combined objective measures with validated selfreported measures in both pre- and post-test phases. This triangulation method of evaluation is vital for providing solid evidence on the effect of the preventive measures under investigation.

Overall, the dental hygienists wearing loupes in this study did not perceive any improvements, based on the results of the self-reported measure of neck pain and disability. On the other hand, we should consider it encouraging that they did not report deterioration in musculoskeletal health. The students who did not wear loupes noted a worsening in their neck pain symptoms; this is unsurprising, given that many studies have found that increasing time spent practicing correlates with reported MSD [16-18]. Improvements were noted for cervical range of motion and low load craniovertebral flexion in the treatment group. Interestingly, these markers deteriorated in the student group which again, may indicate that time practising as a hygienist is a risk factor and that the intervention may have the potential to mitigate deterioration in these measures.

Observed increases in neck extension, flexion, lateral flexion and rotation for those wearing loupes suggest that the muscle activity in this area is not impaired, and as such, injuries to the soft tissues of the neck are less likely. It is also likely that global muscle overactivity and concomitant tightness were reduced, a finding that is consistent with the craniocervical flexion results. Noted improvements in low load cervical vertebral flexion for the treatment group reflect the tonic function of the deep cervical flexor muscles, suggesting less inhibition due to neck pain and greater fine motor control of the cervical spine and its lordosis in the neutral position $[35,36]$. It has been suggested that a neutral posture adopted whilst wearing loupes reduces neck muscle activation [37]. It might also be considered that simply by participating in the study that the hygienists were inherently more aware of their neck positioning, contributing to this positive change.

Wearing loupes appeared to impair the subject's ability to sense the position, orientation and movement of the head and neck [cervical joint position sense]. While wearing loupes, the eyes move between the magnified and unmagnified fields, which can be disconcerting [25]; this perhaps disturbs sensorimotor function though the provision of varying or discordant sensorimotor inputs. It is widely

Table 4

Self reported and physical measures of neck related performance for each participant group

\begin{tabular}{lccccccc}
\hline & \multicolumn{2}{c}{ Loupes wearing group $N=12$} & & & \multicolumn{2}{c}{ Control group $N=17$} \\
\cline { 2 - 3 } & & Baseline Mean (SD) & $\begin{array}{c}\text { Post intervention } \\
\text { Mean (SD) }\end{array}$ & Change & & $\begin{array}{c}\text { Baseline } \\
\text { Mean (SD) }\end{array}$ & $\begin{array}{c}\text { Post intervention } \\
\text { Mean (SD) }\end{array}$ \\
\hline Neck Pain Disability Scale & $14.00(12.49)$ & $14.00(11.05)$ & 0 & & $14.97(16.91)$ & $13.90(13.54)$ & - \\
Low Load Craniocervical flexion (score/100) & $51.83(34.05)$ & $54.17(33.57)$ & + & & $57.88(33.88)$ & $52.18(29.45)$ & - \\
Cervical flexion/extension (degrees) & $51.11(8.09)$ & $52.47(5.45)$ & + & $56.78(5.88)$ & $54.42(4.82)$ & - \\
Craniovertebral Angle (degrees) & $49.69(6.05)$ & $46.91(4.57)$ & - & & $47.86(7.55)$ & $48.65(4.63)$ & + \\
Lateral Flexion (degrees) & $42.50(11.15)$ & $46.33(7.67)$ & + & $49.76(6.49)$ & $48.39(6.21)$ & - \\
Rotation (degrees) & $63.33(8.21)$ & $65.83(5.97)$ & + & $68.71(8.49)$ & $65.79(6.34)$ & - \\
Joint Position Error (centimetres) & $11.71(4.69)$ & $13.22(5.74)$ & - & $16.00(6.44)$ & $12.11(3.87)$ & + \\
\hline
\end{tabular}


acknowledged that wearing loupes requires an adjustment period [25], and while it has been suggested that two to three weeks may be sufficient, perhaps the true adjustment period is longer than this. Conversely, the students' joint position sense was improved in the follow up assessment; this is not surprising, as muscle memory and hand-eye co-ordination should improve for students as they gain experience and transition into their professional careers.

The decline in craniovertebral angle measurement for the hygienists indicates that following the use of loupes, they adopted a more forward head posture. However, it should be noted that in the current study, the mean change was less than $1^{\circ}$; perhaps this change is too small to be considered meaningful, and may be within the error of the measurement method. Interestingly, while the test itself is reliable and widely used, an analysis of studies comparing forward head posture between subjects with pain and asymptomatic subjects concluded that its use in determining health gains should be re-appraised [38]. In the current study, there was no discernible difference in perceived neck pain and baseline and post-intervention for the hygienists [as measured by the NPDS], however the students perceived an increase in neck pain while their forward head posture improved; this contradictory result may lend support to the conclusions of the aforementioned analysis.

The findings from this study compel us to consider that no single intervention may be effective in preventing or limiting MSD among dental hygienists. Rather, as numerous risk factors contribute to MSD, the solution too may be multi-factorial. This has been suggested elsewhere [3,39], and in a review of interventions to reduce work-related MSD, multicomponent interventions found to be more efficacious than single interventions [40]. The lack of statistically significant findings should also lead us to question the value of the self-reported and physical measures used, in measuring MSD in a population with sub-clinical levels of pain. While all measures have demonstrated reliability, they may not be sensitive enough to detect a change when MSD is slight or intermittent.

\subsection{Strengths of the study}

This research is unique, in that it utilised triangulation methods in a longitudinal study to measure loupes as a preventive measure or intervention for MSD. The use of physical measures to assess dental hygienists has been underutilised and in the few studies which attempt this, explicit standardised pro- tocols have not been reported. In a five-year follow up of female dental personnel, it is claimed that a standardised protocol was adhered to for the physical assessment [6]. However, it seems only broad criteria for pain and palpable tenderness was stated rather than explicit and reproducible techniques. Similarly, a physical examination protocol examining the prevalence of carpal tunnel syndrome and upper extremity tendonitis among American hygienists did not report specific methodologies [41]. Furthermore, repeated physical measures have not been used previously when investigating MSD among dental hygienists. Previous studies have used physical examinations as a measure of real time muscle activities (electromyography) [22, 37, 42] and positions (goniometry) [42, 43] or sensory perception ability (vibrometry) [44]. However, these studies fail to record changes in musculoskeletal symptoms over time.

\subsection{Limitations}

In Australia, while the dental hygiene profession is rapidly growing, it nevertheless remains a small and relatively young cohort when considered from an international perspective. As such, the recruitment of participants for this study was challenging, given the small numbers in the profession and the geographic distances required to travel for the physical assessments. At the current time it also remains unclear exactly how many practising hygienists are already wearing loupes, a situation which was a clear exclusion criteria in the current study. Another factor was the potential for confounding variables, such as the type of operator chair used, the type of practice worked in, and patient scheduling including breaks. However, as previously noted recruitment of participants was difficult, and further limiting the inclusion and exclusion criteria may have resulted in evener fewer participants, and the study would not have been viable. Despite the risk of potential confounders, this study allowed participants to work in their usual clinical settings over an extended period, which ensures authenticity.

\section{Conclusions}

This study investigated the effect of loupes on MSD in dental hygienists, using previously validated objective measures, for what appears to be the first time. Overall, no differences were detected between wearing loupes and the control group, or from base- 
line to follow-up. Despite this, the findings do suggest that wearing loupes probably has both positive and negative outcomes in regards to physical well-being. As such, further studies are required to definitively determine the effects of loupes on MSD among dental hygienists, particularly in the long-term.

\section{Acknowledgments}

The authors would like to acknowledge Laura Bevan for her assistance with data collection, and Rachael Moir for her assistance with data entry. We would also like to acknowledge the support of the Dental Hygienists Association of Australia and Care Optical Industrial Co.

\section{Conflict of interest}

Melanie Hayes was a recipient of a financial grant, administered through the Dental Hygienists Research Fund. Care Optical Industrial Co. provided in-kind support by providing the loupes at cost-price. Neither organisation was involved directly in the research project, or in the preparation of this manuscript.

\section{References}

[1] Puriene A, Janulyte V, Musteikyte M, Bendinskaite R. General health of dentists. Literature review. Stomatologija 2007;9(1): 10-20.

[2] Hayes MJ, Cockrell D, Smith DR. A systematic review of musculoskeletal disorders among dental professionals. Int J Dent Hyg 2009;7(3):159-65.

[3] Hayes MJ, Smith DR, Cockrell D. An international review of musculoskeletal disorders in the dental hygiene profession. Int Dent J 2010;60:343-52.

[4] Leggat PA, Kedjarune U, Smith DR. Occupational health problems in modern dentistry. Ind Health 2007;45:611-21.

[5] Michalak-Turcotte C. Controlling dental hygiene workrelated musculoskeletal disorders: The ergonomic process. J Dent Hyg 2000;74(1):41-8.

[6] Akesson I, Johnsson B, Rylander L, Moritz U, Skerfving S. Musculoskeletal disorders among female dental personnel-clinical examination and a 5-year follow-up study of symptoms. Int Arch Environ Occup Med 1999;72:395403.

[7] Hayes MJ, Smith DR, Cockrell D. Prevalence and correlates of musculoskeletal disorders among Australian dental hygiene students. Int J Dent Hyg 2009;7(3):176-81.

[8] Lalumandier JA, McPhee SD, Parrott CB, Vendemia M. Musculoskeletal pain: Prevalence, prevention, and differences among dental office personnel. Gen Dent 2001;49(2): $160-6$.
[9] Ylipaa V, Arnetz BB, Benko SS, Ryden H. Physical and psychosocial work environments among Swedish dental hygienists: Risk indicators for musculoskeletal complaints. Swed Dent J 1997;21(3):111-20.

[10] Ylipaa V, Arnetz BB, Preber H. Factors that affect health and well-being in dental hygienists; a comparison of Swedish dental practices. J Dent Hyg 1999;73(4):191-9.

[11] Warren N. Causes of musculoskeletal disorders in dental hygienists and dental hygiene students: A study of combined biomechanical and psychosocial risk factors. Work 2010;35:441-54.

[12] Smith DR, Wei N, Zhang Y, Wang R. Musculoskeletal complaints and psychosocial risk factors among physicians in mainland China. Int J Ind Ergon 2006;36:599-603.

[13] Smith DR, Wei N, Zhou L, Wang RS. Musculoskeletal complaints and psychosocial risk factors among Chinese hospital nurses. Occup Med 2004;54:579-82.

[14] AlWazzan KA, Almas K, ElShethri SE, AlQuahtani MQ. Back and neck problems among dentists and dental auxiliaries. J Cont Dent Prac 2001;2(3):1-10.

[15] Crawford L, Gutierrez G, Harber P. Work environment and occupational health of dental hygienists: A qualitative assessment. J Occ Envir Med 2005;47:623-32.

[16] Anton D, Rosecrance J, Merlino L, Cook T. Prevalence of musculoskeletal symptoms and carpal tunnel syndrome among dental hygienists. Am J Ind Med 2002;42:248-57.

[17] Liss GM, Jesin E, Kusiak RA, White P. Musculoskeletal problems among Ontario dental hygienists. Am J Ind Med 1995;28:521-40.

[18] Hayes MJ, Taylor JA, Smith DR. Predictors of work-related musculoskeletal disorders among dental hygienists. Int J Dent Hyg 2012;10(4):265-9.

[19] Ylipaa V, Arnetz BB, Preber H. Predictors of good general health, well-being, and musculoskeletal disorders in Swedish dental hygienists. Acta Odont Scand 1999;57(5): 277-82.

[20] Branson BG, Bray KK, Gadbury-Amyot C, Holt LA, Keselyak NT, Mitchell TV, Williams KB. Effect of magnification lenses on student operator posture. J Dent Ed 2004;68(3):384-9.

[21] Maillet JP, Millar AM, Burke JM, Maillet MA, Maillet WA, Neish NR. Effect of magnification loupes on dental hygiene student posture. J Dent Ed 2008;72(1):33-44.

[22] Dong H, Barr A, Loomer P, Laroche C, Young E, Rempel $\mathrm{D}$. The effects of periodontal instrument handle design on hand muscle load and pinch force. JADA 2006;137(8): 1123-30.

[23] Dong H, Loomer P, Barr A, Laroche C, Young E, Rempel D. The effect of tool handle shape on hand muscle load and pinch force in a simulated dental scaling task. Appl Ergo 2007;38(5):525-31

[24] Branson BG, Black MA, Simmer-Beck M. Changes in posture: A case study of a dental hygienist's use of magnification loupes. Work 2010;35:467-76.

[25] Sunell S, Rucker L. Surgical magnification in dental hygiene practice. Int J Dent Hyg 2004;2(1):26-35.

[26] Thomas J, Thomas F. Dental hygienists' opinion about loupes in education. J Dent Hyg 2007;81(4):1-12.

[27] Rucker L, Sunell S. Ergonomic risk factors associated with clinical dentistry. J Calif Dent Assoc 2002;30(2):139-48.

[28] Sunell S, Rucker L. Ergonomic risk factors associated with clinical dental hygiene practice. Probe 2003;37(4):159-66.

[29] Goolkasian P, Wheeler A, Gretz S. The neck pain and disability scale: Test-retest reliability and construct validity. Clin J Pain 2002;18(4):245-50. 
[30] Youdas J, Carey J, Garrett T. Reliability of measurements of cervical spine range of motion - comparison of three methods. Phys Ther 1991;71(2):98-106.

[31] Jull G, Barrett C, Magee R, Ho P. Further characterisation of muscle dysfunction in cervical headache. Cephalalgia 1999;19:179-85.

[32] Treleaven J. Sensorimotor disturbances in neck disorders affecting postural stability, head and eye movement control. Man Ther 2008;13:2-11.

[33] Revel M, Andre-Deshays C, Minguet M. Cervicocephalic kinesthetic sensibility in patients with cervical pain. Arch Phys Med Rehab 1991;72:288-91.

[34] Watson D, Trott P. Cervical headache: An investigation of natural head posture and upper cervical flexor muscle performance. Cephalalgia 1993;13:272-84.

[35] Osmotherly P, Attia J, Thakkinstian A. Can clinical measures of upper quarter postural muscle performance predict neck pain in visual display terminal operators? J Back Musc Rehab 2008;21:113-20.

[36] Jull G. Deep cervical flexor muscle dysfunction in whiplash. J Musc Pain 2000;8(1/2):143-54.

[37] Smith CA, Sommerich CM, Mirka GA, George MC. An investigation of ergonomic interventions in dental hygiene work. Int J Dent Hyg 2002;33(2):175-84.

[38] Silva AG, Punt TD, Sharples P, Vilas-Boas JP, Johnson MI. Head posture assessment for patients with neck pain: Is it useful? Int J Ther Rehab 2009;16(1):43-53.
[39] Boocock MG, McNair PJ, Larmer PJ, Armstrong B, Collier J, Simmonds M, Garrett N. Interventions for the prevention and management of neck/upper extremity musculoskeletal conditions: A systematic review. Occup Environ Med 2007;64:291-303.

[40] Silverstein B, Clark R. Interventions to reduce work-related musculoskeletal disorders. J Electromyography Kinesiol 2004; 14:135-52.

[41] Werner RA, Hamann C, Franzblau A, Rodgers PA. Prevalence of carpal tunnel syndrome and upper extremity tendinitis among dental hygienists. J Dent $\mathrm{Hyg}$ 2002;76(2):126-32.

[42] Bramson J, Smith S, Romagnoli G. Evaluating dental office ergonomics: Risk factors and hazards. JADA 1998;129(2): 174-83.

[43] Hawn C, Tolle S, Darby M, Walker M. A laboratory study to determine the effects of universal and rotating ultrasonic inserts on wrist movement and scaling time efficiency of dental hygienists. Int J Dent Hyg 2006;4(1):15-23.

[44] Conrad JC, Osborn JB, Conrad KJ, Jetzer TC. Peripheral nerve dysfunction in practicing hygienists. J Dent Hyg 1990;64(8):382-7. 